\title{
Disturbance intensity is a stronger driver of biomass recovery than remaining tree-community attributes in a managed Amazonian forest
}

\author{
Angela L. de Avila ${ }^{1}$ (D) | Masha T. van der Sande ${ }^{2}$ | Carsten F. Dormann ${ }^{3}$ | \\ Marielos Peña-Claros ${ }^{2}$ | Lourens Poorter ${ }^{2}$ | Lucas Mazzei $^{4}$ | Ademir R. Ruschel ${ }^{4}$ | \\ José N. M. Silva ${ }^{5}$ | João O. P. de Carvalho ${ }^{5}$ Jürgen Bauhus ${ }^{1}$
}

${ }^{1}$ Chair of Silviculture, Faculty of Environment and Natural Resources, University of

Freiburg, Freiburg, Germany

${ }^{2}$ Forest Ecology and Forest Management Group, Wageningen University and Research, Wageningen, The Netherlands

${ }^{3}$ Biometry and Environmental System Analysis, Faculty of Environment and Natural Resources, University of Freiburg, Freiburg, Germany

${ }^{4}$ Embrapa Amazônia Oriental, Belém, Brazil

${ }^{5}$ Universidade Federal Rural da Amazônia, Belém, Brazil

Correspondence

Angela L. de Avila

Email: angeladeavila@gmail.com

\section{Funding information}

National Council for Scientific and Technological Development, Grant/Award Number: 483831/2011-5; Embrapa, Grant/ Award Number: SEG.03.12.00.030.00; German Academic Exchange Service; MüllerFahnenberg Foundation; European Union Seventh Framework Programme, Grant/ Award Number: 283093 (ROBIN-project); Dutch Ministry of Economic Affairs, Grant/ Award Number: KB-14-003-030; Stichting Het Kronendak, Alberta Mennega Stichting, Treub Maatschappij

Handling Editor: Sharif Mukul

\section{Abstract}

1. Forest recovery following management interventions is important to maintain ecosystem functioning and the provision of ecosystem services. It remains, however, largely unclear how above-ground biomass (AGB) recovery of species-rich tropical forests is affected by disturbance intensity and post-disturbance (remaining) tree-community attributes, following logging and thinning interventions.

2. We investigated whether annual $A G B$ increment ( $\triangle A G B$ ) decreases with management-related disturbance intensity (disturbance hypothesis), and increases with the diversity (niche-complementarity hypothesis) and the communityweighted mean (CWM) of acquisitive traits of dominant species (biomass-ratio hypothesis) in the remaining tree community.

3. We analysed data from a long-term forest-management experiment in the Brazilian Amazon over two recovery periods: post-logging (1983-1989) and post-thinning (1995-2012). We computed the $\triangle A G B$ of surviving trees, recruit trees and of the total tree community. Disturbance intensity was quantified as basal area reduction and basal area remaining. Remaining diversity (taxonomic, functional and structural) and CWM of five functional traits linked to biomass productivity (specific leaf area, leaf nitrogen and phosphorous concentration, leaf toughness and wood density) were calculated for the post-intervention inventories. Predictors were related to response variables using multiple linear regressions and structural equation modelling.

4. We found support for the disturbance hypothesis in both recovery periods. AGB increment of survivors and of the total tree community increased with basal area remaining, indicating the importance of remaining growing stock for biomass recovery. Conversely, AGB increment of recruit trees increased with basal area reduction because changes in forest structure increased resource availability for young trees. We did not find consistent support for the niche-complementarity and biomass-ratio hypotheses, possibly because of a high redundancy in these extremely species-rich forests. 
5. Synthesis and applications. The intensity of disturbance through management, expressed as basal area reduction and basal area remaining, was consistently more important for explaining forest biomass recovery following harvesting and thinning than remaining diversity or trait composition. This points to the importance of controlling logging and thinning intensity in forests of the eastern Amazon. Given the high intervention intensities applied in this experiment, it is likely that low to moderate harvesting intensities permitted by the current legislation for the Brazilian Amazon (30 $\mathrm{m}^{3} / \mathrm{ha}$ ) will not impair biomass recovery in these forests.

\section{KEYWORDS}

biomass and forest recovery, biomass-ratio hypothesis, disturbance intensity, functional traits, niche-complementarity hypothesis, selective logging, species and structural diversity, stand thinning

\section{1 | INTRODUCTION}

The resilience of tropical forests to management interventions is essential to guarantee a long-term functioning and provisioning of ecosystem services. The recovery of above-ground biomass (AGB) determines the potential for climate change mitigation and may be related to the restoration of other forest attributes such as timber stocks (Feldpausch, McDonald, Passos, Lehmann, \& Riha, 2006), biodiversity and species composition (Chazdon et al., 2007). AGB recovery is driven by the growth of surviving and recruit trees following disturbances and can be affected by the disturbance regime (Miller et al., 2011), site conditions and remaining biological legacies (Chazdon, 2003). In managed forests of the Amazon Basin, there has been much interest on understanding post-logging AGB dynamics, and studies have indicated that disturbance intensity (Rutishauser et al., 2015; Vidal, West, \& Putz, 2016) and remaining forest structure (Piponiot et al., 2016; Rutishauser et al., 2015) play a crucial role for AGB recovery. However, there is little information regarding the influence of tree-community attributes and of subsequent, management-related disturbances such as thinning on the recovery of AGB (but see van der Sande et al., 2017). This knowledge is, however, essential to assess the resilience of managed tropical forests.

The degree of disruption in the canopy through logging determines the change in forest microclimate and affects ecosystem functions such as productivity (Miller et al., 2011). On the one hand, management interventions can promote AGB recovery owing to enhanced growth of remaining trees through increase in resource availability and reduction in site occupancy (Assmann, 1961). On the other hand, a high-intervention intensity can impair AGB recovery due to pronounced damage and changes in forest structure that lead to high stress and reduced growth of remaining trees (e.g. de Graaf, Poels, \& van Rompaey, 1999; West, Vidal, \& Putz, 2014). Here, we tested the hypothesis that AGB recovery decreases with the management-related disturbance intensity (disturbance hypothesis; Figure 1). Additionally, each type of intervention has different implications for forest structure and dynamics. For instance, owing to the

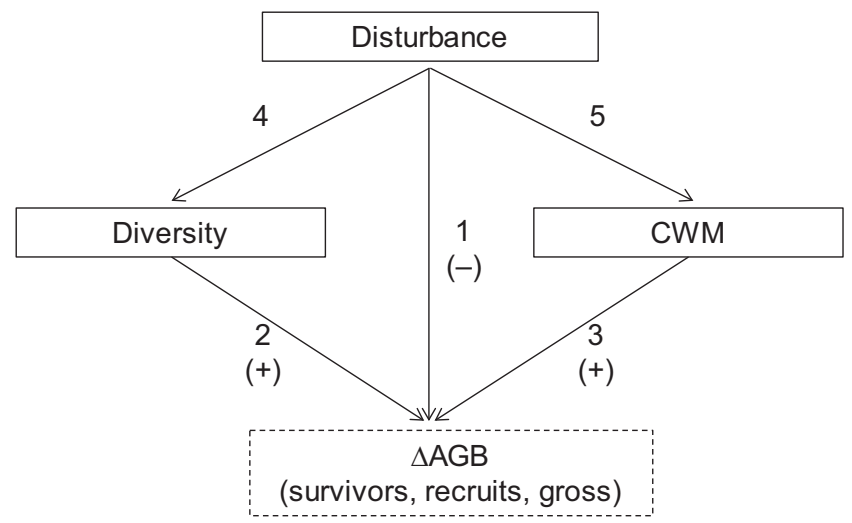

FIGURE 1 Conceptual model used to examine the integrated effects of disturbance intensity, remaining diversity and community-weighted mean (CWM) values of five functional traits on annual above-ground biomass increment ( $\triangle \mathrm{AGB}-$ dashed box) of surviving, recruit trees and of total community (gross increment). Arrows 1-3 indicate the tested hypotheses with the sign of the expected relationship: (1) disturbance hypothesis; (2) nichecomplementarity hypothesis; and (3) biomass-ratio hypothesis. Arrows 4 and 5 indicate indirect effects of disturbance on $\triangle A G B$ through diversity or CWM values

common asymmetry of competition, harvesting of large trees has a more pronounced effect on availability of light and other resources than thinning of understorey trees, while post-logging interventions may further influence biomass dynamics.

The attributes of the remaining vegetation will be also affected by disturbance intensity and may affect growth and AGB recovery through the following two underlying mechanisms. Firstly, it is expected that functional complementarity among species enhances overall resource use (i.e. the complementarity effect; Loreau, 2000). Such effect can be captured through the diversity in species, traits, or sizes that may lead to niche differentiation. Secondly, instead of the overall diversity, it may be that dominant species in the community and their traits drive ecosystem functioning (i.e. mass-ratio theory; Grime, 1998). The effect of trait dominance can be captured by 
the community-weighted mean (CWM; Violle et al., 2007) of traits that are related to the process of interest. For instance, high-specific leaf area (SLA) increases light interception efficiency (Shipley, 2006), leaf nitrogen and phosphorous concentration enhance photosynthesis (Mercado et al., 2011) and should therefore enhance growth and recovery. Conversely, high leaf toughness reduces leaf expansion and light capture, and thus may be negatively related to growth (Kitajima et al., 2012). As stem trait, wood density increases tree longevity (Poorter et al., 2008) but is negatively related to growth rates (Chave et al., 2009; Finegan et al., 2015).

Above-ground biomass recovery following disturbances may, therefore, increase with remaining diversity through more efficient resource use (niche-complementarity hypothesis; Figure 1), or with trait values of dominant species that enhance resource acquisition (biomass-ratio hypothesis; Figure 1). In unmanaged tropical forests, AGB growth has been reported to be positively related to diversity (e.g. phylogenetic and functional diversity; Lasky et al., 2014) and important traits of the tree community (e.g. high SLA and low wood density; Finegan et al., 2015). In managed tropical forests, however, the effects of logging with subsequent silvicultural interventions as well as the influence of remaining diversity on AGB recovery remain largely unknown. Here, we investigated these effects on the annual above-ground biomass increment $(\triangle A G B)$ following logging (1983-1989) and thinning (1995-2012). To better understand AGB dynamics, we computed $\triangle \mathrm{AGB}$ for surviving and recruit trees separately because they may respond differently to the changes caused by management. We tested the hypotheses that $\triangle \mathrm{AGB}$ :

1. decreases with disturbance intensity (disturbance hypothesis),

2. increases with remaining tree diversity (niche-complementarity hypothesis), and

3. increases with acquisitive traits of dominant species in the remaining tree community (biomass-ratio hypothesis).

\section{2 | MATERIALS AND METHODS}

\section{1 | Study description and data collection}

\subsection{1 | Study area and management experiment}

The forest-management experiment (180 ha) was established in 1981 in the Tapajós National Forest, Pará, Brazil. The topography of the region is flat to slightly undulating and the altitude is around $175 \mathrm{~m}$ above sea level. The climate is tropical (Am in the Köppen classification; Peel, Finlayson, \& McMahon, 2007) with average annual rainfall of $2,000 \mathrm{~mm}$ and one dry season (August to November with a monthly rainfall $<100 \mathrm{~mm}$ ). The predominant soil type is a Dystrophic Yellow Latosol or Oxisol, with heavy clay texture, deep profile and low fertility (De Oliveira Junior et al., 2015). The vegetation is classified as ombrophilous dense forest.

The experiment has a randomised block design with four replicates. Each block (36 ha) is divided into four experimental units ( 9 ha each) where treatments (i.e. a combination of logging and subsequent thinning of different intensities) were randomly applied (see detailed description in Appendix S1 and Figure S1; de Avila et al., 2015). In each experimental unit, three permanent sample plots ( $50 \times 50 \mathrm{~m}$ or 0.25 ha each) were established at random, with a total of 12 plots per treatment and 48 plots in total. In 1983, a 36-ha block of unlogged forest was added with 12 permanent sample plots (0.25 ha each).

Logging, which removed only trees above $45 \mathrm{~cm}$ in $\mathrm{DBH}$, was carried out in 1982 and thinning was done in 1993/1994. The basal area reduction through logging in each plot ranged from 1 to $19 \mathrm{~m}^{2} /$ ha. The non-commercial thinning was done through poisongirdling of non-commercial stems $(\mathrm{DBH}>15 \mathrm{~cm})$ in a uniform distribution across the stand to reduce competition and promote growth of commercial timber species. The basal area reduction in each plot through thinning ranged from 0.4 to $11.3 \mathrm{~m}^{2} / \mathrm{ha}$. An accidental fire affected 19 permanent sample plots in 1997. Since burned plots were temporarily not inventoried after the fire, these plots were not considered in this study. Permanent sample plots were monitored on eight inventories (1981, 1983, 1987, 1989, 1995, 2003, 2008 and 2012) and trees with diameter at breast height $(\mathrm{DBH}) \geq 5 \mathrm{~cm}$ were permanently labelled and measured.

We used data from the 41 unburned plots and considered only the tree community comprising individuals with $\mathrm{DBH} \geq 10 \mathrm{~cm}$ to permit comparisons with published results and because poles $(5 \leq \mathrm{DBH}<10 \mathrm{~cm}$ ) represented only a small proportion ( $<1 \%)$ of the $A G B$ at the plot level. In this study, the management-related disturbance intensity of each plot was considered, which ranged from 0 in unmanaged plots to around $50 \%$ basal area reduction relative to predisturbance levels in the most disturbed plots (see Table 1 for descriptive statistics). Pre-logging basal area was on average $28( \pm 5.6)$ $\mathrm{m}^{2} /$ ha among the 35 logged plots. We considered the two recovery periods, post-logging (1983-1989) and post-thinning (1995-2012), separately. We adopted this approach because (1) thinning, which likely influences AGB dynamics, was applied 11 years after harvesting in 25 of the 35 logged plots, and (2) we have no treatments where only thinning was applied and therefore could not test for effects of thinning only.

\subsection{2 | Trait collection}

Four leaf traits were measured for 68 tree species and one stem trait for 62 tree species. These sampled species represent $21 \%$ of all tree species (319) identified in the study area but contributed on average to $69 \%$ of the basal area in each plot. All sampled species were identified to the species level except for one that was identified to the genus level (Apeiba spp.) and two to the family level (Lauraceae and Sapotaceae). Five leaves were sampled for 1-11 trees $(10-20 \mathrm{~cm}$ $\mathrm{DBH}$ ) per species. After collection, leaves were separated from their petiole to measure the following leaf traits according to standard protocols (Pérez-Harguindeguy et al., 2013): SLA ( $\mathrm{cm}^{2} / \mathrm{g}$ ), nitrogen $\left(\mathrm{N}_{\text {leaf }}\right)$ and phosphorous $\left(\mathrm{P}_{\text {leaf }}\right)$ concentration (\% per unit leaf dry mass), and specific force to punch (FPs, $\mathrm{N} / \mathrm{m}^{2}$ ) as a measure of leaf 
TAB LE 1 Descriptive statistics for response and predictor variables used to test the effect of disturbance intensity and remaining tree-community attributes on annual AGB (above-ground biomass) increment of a managed Amazonian forest over two recovery periods ( $n=41$ plots)

\begin{tabular}{|c|c|c|c|c|c|c|}
\hline & \multicolumn{3}{|c|}{ Post-logging (1983-1989) } & \multicolumn{3}{|c|}{ Post-thinning (1995-2012) } \\
\hline & Mean $( \pm S D)$ & Min & Max & Mean $( \pm S D)$ & Min & Max \\
\hline $\begin{array}{l}\text { Annual AGB increment-survivors ( } \triangle \mathrm{AGB}_{\text {survivors' }} \\
\mathrm{Mg} \mathrm{ha}^{-1} \text { year }^{-1} \text { ) }\end{array}$ & $6.74( \pm 1.37)$ & 3.62 & 9.45 & $5.28( \pm 1.28)^{* * *}$ & 2.89 & 8.57 \\
\hline $\begin{array}{l}\text { Annual AGB increment-recruits ( } \triangle \mathrm{AGB}_{\text {recruits' }} \\
\mathrm{Mg} \mathrm{ha}^{-1} \text { year }^{-1} \text { ) }\end{array}$ & $0.90( \pm 1.09)$ & 0.01 & 4.21 & $0.73( \pm 0.62)$ & 0.05 & 2.56 \\
\hline $\begin{array}{l}\text { Gross annual AGB increment ( } \triangle \mathrm{AGB}_{\text {gross' }} \\
\mathrm{Mg} \mathrm{ha}^{-1} \text { year }^{-1} \text { ) }\end{array}$ & $7.64( \pm 1.38)$ & 5.28 & 11.69 & $6.00( \pm 1.05)^{* * *}$ & 3.72 & 8.94 \\
\hline \multicolumn{7}{|l|}{ Management-related disturbance intensity } \\
\hline $\begin{array}{l}\text { Proportion of basal area reduction }\left(\mathrm{BA}_{\text {reduction }}\right) \\
\text { through logging and damage relative to } 1981\end{array}$ & $0.14( \pm 0.13)$ & 0.00 & 0.47 & - & - & - \\
\hline Basal area remaining in $1995\left(\mathrm{BA}_{\text {remaining, }}, \mathrm{m}^{2} / \mathrm{ha}\right)$ & - & - & - & $24.53( \pm 5.44)$ & 14.48 & 37.05 \\
\hline \multicolumn{7}{|l|}{ Post-disturbance (remaining) diversity } \\
\hline Rarefied number of species (Srar) & $42.8( \pm 4.8)$ & 33.9 & 52.1 & $43.2( \pm 4.4)$ & 34.2 & 55.4 \\
\hline Functional dispersion (FDis) & $0.14( \pm 0.02)$ & 0.10 & 0.19 & $0.16( \pm 0.02)$ & 0.12 & 0.21 \\
\hline Gini coefficient (Gini) & $0.58( \pm 0.06)$ & 0.45 & 0.68 & $0.58( \pm 0.05)$ & 0.48 & 0.70 \\
\hline \multicolumn{7}{|c|}{ Post-disturbance (remaining) community-weighted mean (CWM) trait values } \\
\hline CWM-Specific leaf area (SLA, $\mathrm{cm}^{2} / \mathrm{g}$ ) & $134.84( \pm 11.28)$ & 114.39 & 158.37 & $137.04( \pm 10.81)$ & 115.43 & 171.06 \\
\hline CWM-Leaf nitrogen concentration ( $\left.\mathrm{N}_{\text {leaf }}, \%\right)$ & $2.14( \pm 0.16)$ & 1.84 & 2.51 & $2.20( \pm 0.15)$ & 1.90 & 2.57 \\
\hline CWM-Leaf phosphorous concentration ( $\left.\mathrm{P}_{\text {leaf, }} \%\right)$ & $0.10( \pm 0.01)$ & 0.09 & 0.13 & $0.11( \pm 0.01)$ & 0.09 & 0.14 \\
\hline
\end{tabular}

$S D$, standard deviation; Min, minimum; and Max, maximum value observed.

Asterisks after the mean $( \pm S D)$ in the post-thinning period indicate the result of the paired Student's $t$ test for the comparison between post-logging and post-thinning values for AGB increment $\left({ }^{* * *} p<.001\right.$; normality of the distribution of the data was investigated using the Shapiro-Wilk test; $\triangle \mathrm{AGB}_{\text {recruits }}$ was In transformed).

toughness. Wood density (WD, $\mathrm{g} / \mathrm{cm}^{3}$ ) was measured for 1-3 trees $(20-40 \mathrm{~cm} \mathrm{DBH})$ per species taking a wood core at breast height from the outer sapwood until the pith using an increment borer.

\subsection{Estimating AGB and increment}

Above-ground biomass ( $\mathrm{AGB}, \mathrm{Mg}$ ) per tree was computed using the allometric equation from Chave et al. (2014) with diameter, wood density and an environmental stress variable as predictors because it provides reliable AGB estimates when tree height is not available. Values of wood density were obtained from our trait collection and for non-sampled species using a local database (http://sistemas. florestal.gov.br/madeirasdobrasil/default.htm), or in some cases from the Global Wood Density database (http://doi.org/10.5061/ dryad.234, Chave et al., 2009; Zanne et al., 2009). If the point of measurement of diameter was changed between two measurements due to a deformity in the stem at breast height (e.g. buttresses), a mean value between the former and the new diameter was used to compute the AGB in the year with change, as recommended by Talbot et al. (2014).

Annual AGB increment ( $\triangle \mathrm{AGB}$ ) was calculated separately for surviving and recruit trees considering the first and the last inventory in each recovery period. The $\triangle A G B$ of surviving trees ( $\triangle \mathrm{AGB}_{\text {survivors, }}$, $\mathrm{Mg} \mathrm{ha}^{-1}$ year $^{-1}$ ) was calculated by summing the growth in AGB of each surviving tree to obtain the increment at the plot level which was then scaled up to the hectare level. The $\triangle A G B$ of recruit trees $\left(\triangle \mathrm{AGB}_{\text {recruits }}, \mathrm{Mg} \mathrm{ha}^{-1}\right.$ year $^{-1}$ ) was calculated by summing the growth in $A G B$ of each recruit tree and scaling it up from the plot to the hectare level. The AGB growth of each recruit tree was estimated as the $A G B$ in the last inventory minus the $A G B$ of a tree with $10 \mathrm{~cm} \mathrm{DBH}$, assuming that the recruits had the minimum measured diameter in the first inventory (Talbot et al., 2014). The sum of $\triangle A G B_{\text {survivors }}$ and $\triangle A G B_{\text {recruits }}$ provided the gross annual $A G B$ increment ( $\triangle A G B_{\text {gross' }}$, $\mathrm{Mg} \mathrm{ha}^{-1}$ year $^{-1}$ ). 


\section{3 | Factors expected to affect AGB increment}

\subsection{1 | Management-related disturbance intensity}

Disturbance intensity was computed in two ways: as basal area reduction $\left(\mathrm{BA}_{\text {reduction }}\right)$ and as basal area remaining $\left(\mathrm{BA}_{\text {remaining }}\right)$, as they may differently affect AGB recovery. The reduction in basal area will increase resource availability and decrease competition for remaining trees, whereas the basal area remaining is a measure of site occupancy that affects the ability of the ecosystem to recover (Assmann, 1961). For the post-logging recovery period (1983-1989), the $\mathrm{BA}_{\text {reduction }}$ was calculated as the proportion of reduction through tree harvest and damage relative to the pre-logging stand basal area (1981). For the post-thinning recovery period (1995-2012), the proportion of $\mathrm{BA}_{\text {reduction }}$ was calculated relative to the basal area in 1989 and comprised only trees culled through thinning. Finally, basal area remaining ( $\mathrm{BA}_{\text {remaining }}$ ) was defined as the basal area comprising all living trees in the inventories right after logging (1983) and thinning (1995).

\subsection{2 | Remaining diversity and CWM trait values}

Diversity and CWM trait values were calculated for the inventories immediately after logging (1983) and thinning (1995). Taxonomic diversity was calculated as the rarefied number of species (Srar) to the minimum number of stems found in one plot. Functional diversity was defined as the multivariate functional trait dispersion (FDis) in the community based on collected traits. Compared to other functional diversity measures, FDis is less sensitive to incompleteness of the trait data (Pakeman, 2014). Structural diversity was quantified using the Gini coefficient (Gini) of tree basal area as a measure of inequality in tree size distribution, which varies from zero (total size equality) to one (total size inequality) (Weiner \& Solbrig, 1984). CWM trait values were calculated weighting by species' biomass.

\subsection{Statistical analysis}

Since predictors were not strongly correlated they could remain in the analysis (Table S1). Our hypotheses were tested using linear mixed-effect models (LMMs), with block as a random term. Each hypothesis was tested separately for each demographic group using multiple regressions with plots as replicates $(n=41)$. For the disturbance hypothesis, reductions in AGB were highly and significantly correlated with reductions in $\mathrm{BA}(0.97$ for the post-logging and 0.99 for the post-thinning period, $p<.0001)$. Using reductions in AGB as predictor variable produced very similar results as were obtained when using BA reduction (Table S4). Thus, we present here only results using BA reduction as a predictor variable. For the biomassratio hypothesis, we tested whether exclusion of plots with trait coverage lower than $60 \%$ would change results. As this was not the case (except for survivors in the post-logging period, Table S5), we present here results with data from all plots.
Interactions among predictors were tested and only included when they produced a better fit of the model. The significance of interaction terms was tested using a stepwise backwards model selection with model comparison based on the sample adjusted Akaike information criterion ( $\mathrm{AIC}_{\mathrm{c}}$ ). The following interactions were included: (1) $\mathrm{BA}_{\text {reduction }} \times \mathrm{BA}_{\text {remaining }}$ for the post-logging period, because growth rates may be enhanced by $B A_{\text {reduction }}$ when enough $B A_{\text {remaining }}$ is left to enable a better use of available resources; and (2) Srar $\times$ Gini for the post-thinning period, because growth rates may increase with taxonomic diversity that may lead to higher tree size inequality and thus better niche occupancy. After selecting the best fitting model, we computed the sequential sum of squares (ANOVA) to test for the effects of predictors on the response variable. We also centred and standardised variables to obtain the standardised fixed effect coefficients estimates $(\hat{\beta})$. Spatial autocorrelation of model residuals was detected in one case (i.e. disturbance hypothesis for $\triangle \mathrm{AGB}_{\text {gross }}$ in the post-logging period), for which a spatial correlation structure (corExp) was included and did not change results ( $p<.05$ for the interaction $\left.\mathrm{BA}_{\text {reduction }} \times \mathrm{BA}_{\text {remaining }}\right)$.

To integrate the disturbance, niche-complementarity and biomassratio hypotheses, we used structural equation modelling (SEM) that provides the possibility to build a hierarchical model among predictors (Grace, 2006). Here, we used only $\mathrm{BA}_{\text {remaning }}$ as the predictor for disturbance intensity because it captures the accumulated effect of logging and thinning for the post-thinning period. For remaining diversity, we had three possible candidate variables (Srar, FDis and Gini) and for remaining trait values, we had five traits (CWM of SLA, $N_{\text {leaf }}, P_{\text {leaf }}, F P_{s}$ and WD) (see Figure 1 for expected relationships). We included each candidate variable one at a time in the SEM. The fit between models and data was assessed using a $\chi^{2}$ test. The models presented here were selected based on the highest proportion of explained variance $\left(R^{2}\right)$ for AGB increment or $\mathrm{AIC}_{\mathrm{c}}$ when multiple models presented the same $R^{2}$.

To perform the analyses, we employed $\mathrm{R}$ version 3.1.2 ( $\mathrm{R}$ Development Core Team, 2014). The Gini coefficient was computed using the package reldist 1.6-4 (Handcock, 2015). CWM trait values and FDis were calculated using the package FD 1.0-12 (Laliberté, Legendre, \& Shipley, 2015). Linear mixed models were fit with the package nlme 3.1-118 (Pinheiro, Bates, DebRoy, \& Sarkar, 2015). Structural equation models were fit using the package lavaan 0.5-20 (Rosseel et al., 2015).

\section{3 | RESULTS}

Annual above-ground biomass increment $(\triangle A G B)$ of survivors and the total community were significantly higher in the post-logging (1983-1989) than in the post-thinning (1995-2012) period $(p<.001$, Table 1), and overall, remaining basal area was the main driver of AGB recovery in both periods.

\section{1 | Disturbance hypothesis}

Effects of disturbance intensity on $\triangle A G B$ were significant in both periods and for survivors, recruits and gross increment (Tables S2 and S3). Following logging, the interaction between basal area 
remaining $\left(\mathrm{BA}_{\text {remaining }}\right)$ and basal area reduction $\left(\mathrm{BA}_{\text {reduction }}\right)$ was significant for $\triangle A G B$ of surviving trees $\left(\triangle A G B_{\text {survivors }}\right.$ ) and for the whole tree community ( $\triangle \mathrm{AGB}_{\text {gross }}$ ) (Table $\mathrm{S} 2$ ). Here, $\triangle \mathrm{AGB}_{\text {survivors }}$ mainly increased when $B A_{\text {remaining }}$ was above c. $23 \mathrm{~m}^{2} / \mathrm{ha}$, while below this value of $B A_{\text {remaining, }} \triangle A G B_{\text {survivors }}$ declined with increasing $\mathrm{BA}_{\text {reduction }}$ (Figure $2 \mathrm{a}$ ). $\triangle \mathrm{AGB}_{\text {gross }}$ mainly increased with $\mathrm{BA}_{\text {remaining }}$ (Figure 2c). Following thinning, $\triangle A G B_{\text {survivors }}$ decreased with $\mathrm{BA}_{\text {reduction }}$ (Figure 3a) while both $\triangle \mathrm{AGB}_{\text {survivors }}$ and $\triangle A G B_{\text {gross }}$ increased with $B A_{\text {remaining }}$ (Figure $3 c, d$ ). In both periods, $\triangle A G B$ of recruits $\left(\triangle A G B_{\text {recruits }}\right)$ increased with $B A_{\text {reduction }}$ (Figures $2 b$ and $3 b$ ).

\subsection{Niche-complementarity hypothesis}

We found a significant effect of diversity on $\triangle A G B$ in the postthinning period (Tables S2 and S3), where $\triangle \mathrm{AGB}_{\text {gross }}$ increased with structural (Gini) or taxonomic (Srar) diversity (Figure 3e).

\section{3 | Biomass-ratio hypothesis}

We found significant effects of CWM trait values on $\triangle A G B$ in the post-logging period (Tables S2 and S3). The CWM leaf nitrogen concentration ( $C W M N_{\text {leaf }}$ ) was related to an increase in $\triangle A G B_{\text {survivors }}$ (Figure $2 \mathrm{~d}$ ) but a decrease in $\triangle \mathrm{AGB}_{\text {recruits }}$ (Figure 2e).

\subsection{Integrating the three hypotheses}

The SEM clearly indicated that disturbance intensity had stronger effects on $\triangle A G B$ than the attributes of the remaining tree community. This applied to both recovery periods (Figure 4), where $\mathrm{BA}_{\text {remaining }}$ was positively related to $\triangle \mathrm{AGB}_{\text {survivors }}$ and $\triangle \mathrm{AGB} \mathrm{B}_{\text {gross }}$, but negatively with $\triangle A G B_{\text {recruits. }}$ In the post-logging period, $C W M N_{\text {leaf }}$ had a positive effect on $\triangle A G B_{\text {survivors. }}$. Additionally, a moderate and positive indirect effect of disturbance through Gini was observed for $\triangle \mathrm{AGB}_{\text {recruits }}$ (Figure $4 \mathrm{a}$ ). In the post-thinning period both diversity and CWM had no significant effect on $\triangle A G B$ (Figure $4 \mathrm{~b}$ ).

\section{4 | DISCUSSION}

We investigated the effects of management-related disturbance intensity (measured as basal area reduction and basal area remaining) and of post-disturbance tree-community attributes (taxonomic, (a) Survivors (1983-1989)

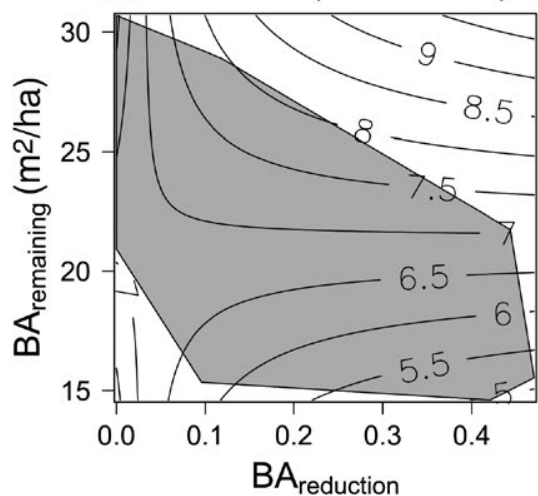

(d) Survivors (1983-1989)

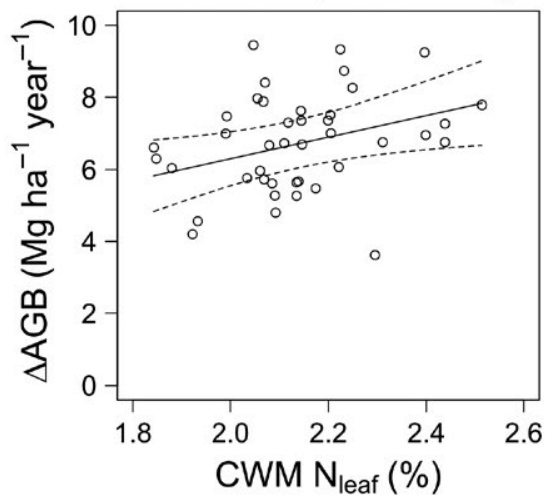

(b) Recruits (1983-1989)

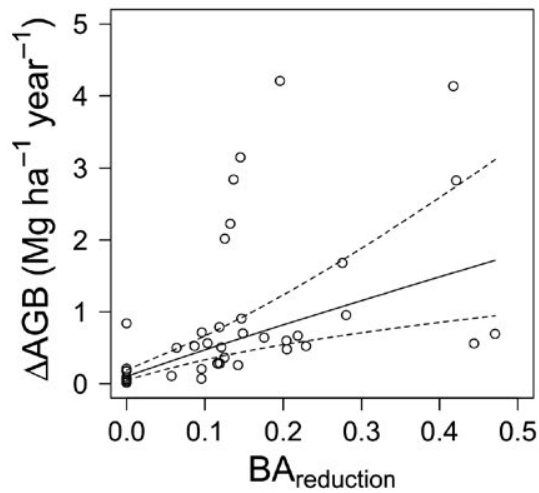

(e) Recruits (1983-1989)

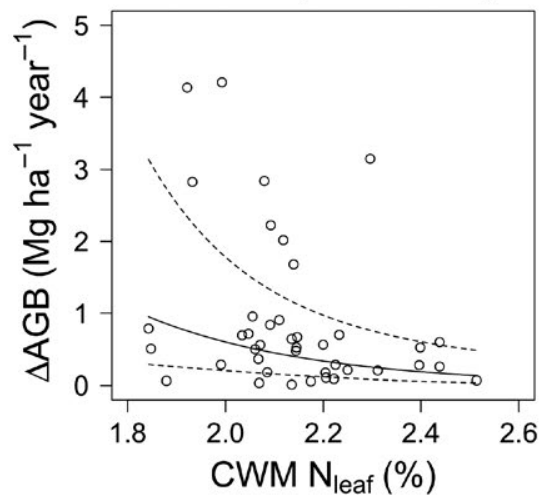

(c) Gross (1983-1989)

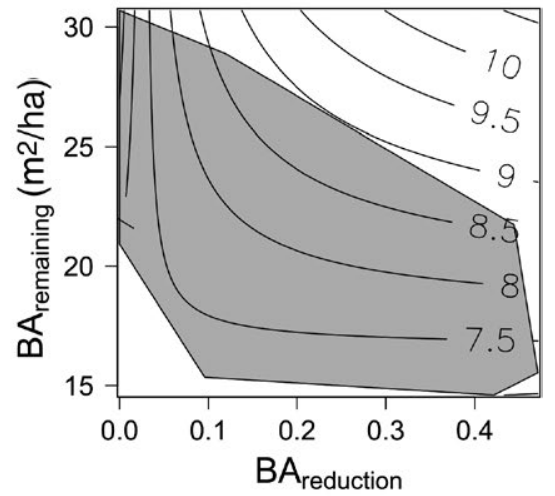

FIGURE 2 Significant relationships for the effects of disturbance intensity and remaining tree-community attributes on the annual AGB (above-ground biomass) increment ( $\triangle \mathrm{AGB}, \mathrm{Mg} \mathrm{ha}^{-1}$ year $^{-1}$ ) of demographic groups in the post-logging period (1983-1989): effect of interaction between basal area reduction $\left(\mathrm{BA}_{\text {reduction }}\right.$ ) and basal area remaining ( $\mathrm{BA}_{\text {remaining }}$ ) on $\triangle \mathrm{AGB}$ of (a) surviving trees and (c) gross increment (surviving + recruit trees), where the contour lines indicate the response variable and non-shaded area indicates absence of data points; (b) effect of $B A_{\text {reduction }}$ on $\triangle \mathrm{AGB}$ of recruit trees; and effect of community-weighted mean (CWM) leaf nitrogen concentration (CWM $\mathrm{N}_{\text {leaf }}$ ) on $\triangle \mathrm{AGB}$ of (d) surviving trees and (e) recruit trees. For results of multiple regressions, see Table S2 and for significance of individual regressions see Table S6 
(a) Survivors (1995-2012)

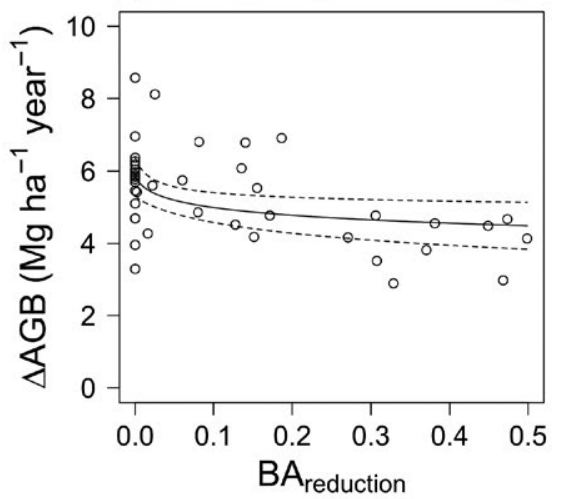

(d) Gross (1995-2012)

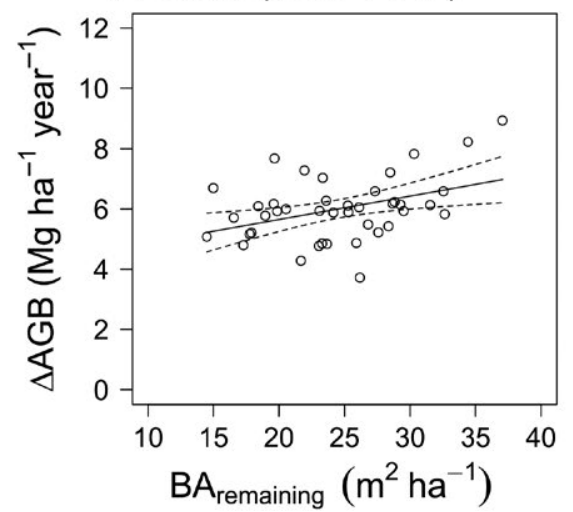

(b) Recruits (1995-2012)

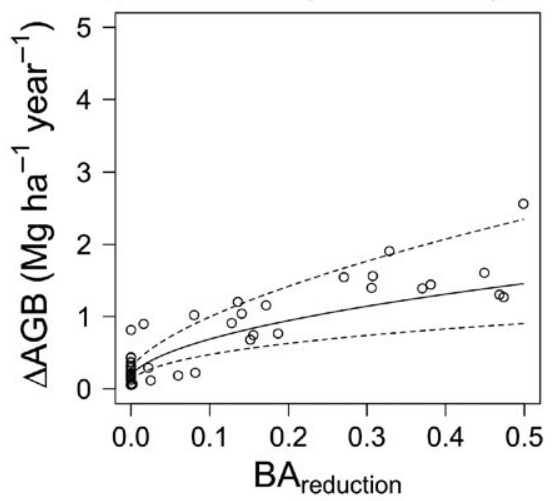

(e) Gross (1995-2012)

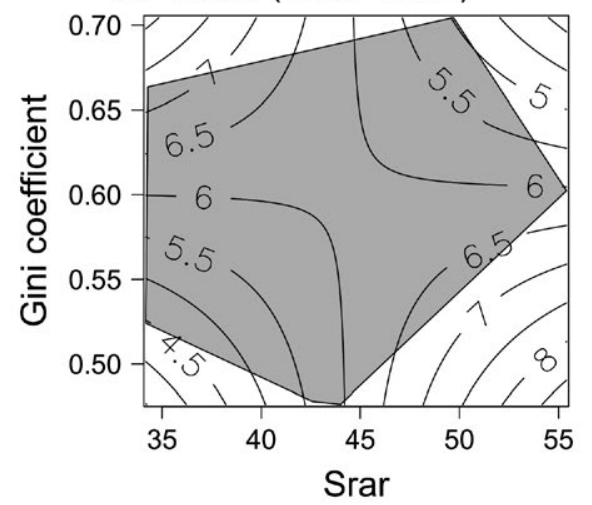

(c) Survivors (1995-2012)

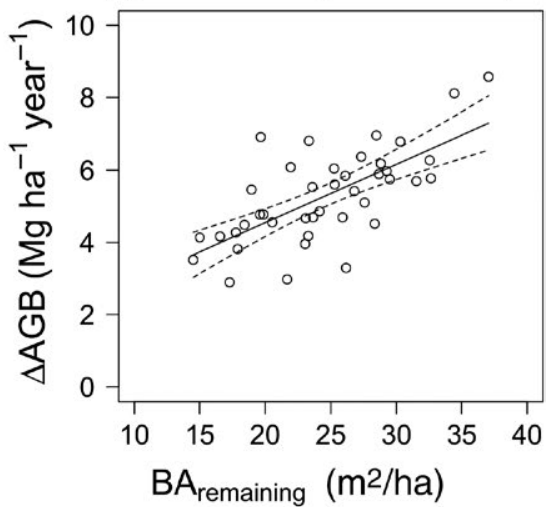

FIGURE 3 Significant relationships for the effects of disturbance intensity and remaining tree-community attributes on the annual AGB (above-ground biomass) increment ( $\triangle \mathrm{AGB}, \mathrm{Mg} \mathrm{ha}^{-1}$ year $^{-1}$ ) of demographic groups in the post-thinning period (1995-2012): effect of reduction in basal area $\left(\mathrm{BA}_{\text {reduction }}\right.$ ) on $\triangle \mathrm{AGB}$ of (a) surviving trees and (b) recruit trees; effect of basal area remaining (BA $\mathrm{B}_{\text {remaining }}$ ) on $\triangle \mathrm{AGB}$ of (c) surviving trees and (d) gross increment (surviving + recruit trees); and (e) effect of interaction between remaining structural (Gini coefficient) and taxonomic (rarefied number of species, Srar) diversity on gross increment, where the contour lines indicate the response variable and non-shaded area indicates absence of data points. For results of multiple regressions, see Table S3 and for significance of individual regressions see Table S6

functional and structural diversity as well as CWM values of five functional traits) on the annual AGB increment $(\triangle A G B)$ of the tree community (survivors, recruits and total community) following logging and thinning interventions. Overall, $\triangle A G B$ was mainly determined by basal area remaining, whereas remaining tree-community attributes had only a minor influence.

\section{1 | Disturbance hypothesis: Disturbance decreased AGB increment of survivors and total community, but increased that of recruits}

The negative effect of disturbance on the annual $A G B$ increment of survivors ( $\triangle A G B_{\text {survivors }}$ ) and of the total community $\left(\triangle A G B_{\text {gross }}\right.$ ) is likely associated with the strong reduction in basal area that took place in the experiment. When the remaining forest has a high basal area, it likely retains a high level of site occupancy enabling a better use of available resources (Assmann, 1961). Here, the importance of remaining growing stock for AGB recovery was indicated by the significant positive effect of the basal area remaining (BA $A_{\text {remaining; }}$ Figures 2-4) and a stronger effect of $\mathrm{BA}_{\text {remaining }}$ than of basal area reduction ( $B A_{\text {reduction; }}$ see $\hat{\beta}$ in Tables $S 2$ and S3) on $\triangle A G B_{\text {survivors }}$ and $\triangle A G B_{\text {gross }}$. Such positive effect of $B A_{\text {remaining }}$ may also be attributable to a higher remaining abundance of large trees that are the main contributors to the community biomass growth (Mazzei et al., 2010; Rutishauser, Wagner, Herault, Nicolini, \& Blanc, 2010).

The importance of the remaining growing stock indicates that heavy logging and thinning interventions may impair the AGB recovery so that controlling the intensity of such interventions can help to maintain the resilience of the system. Similar to our results, the remaining growing stock has been documented to be positively related with the post-logging basal area growth in Papua New Guinea (Yosi, Keenan, \& Fox, 2011) and with recovery times of carbon stocks across managed forests in the Amazon Basin (Rutishauser et al., 2015). Likewise, a study in the Brazilian Amazon found higher AGB increment at the community level in less disturbed plots (Vidal et al., 2016).

The increase in $\triangle A G B$ of recruit trees $\left(\triangle A G B_{\text {recruits }}\right)$ with $B A_{\text {reduction }}$ can be attributed to enhanced resource availability (e.g. light and nutrients) and reduced competition in the understorey and 


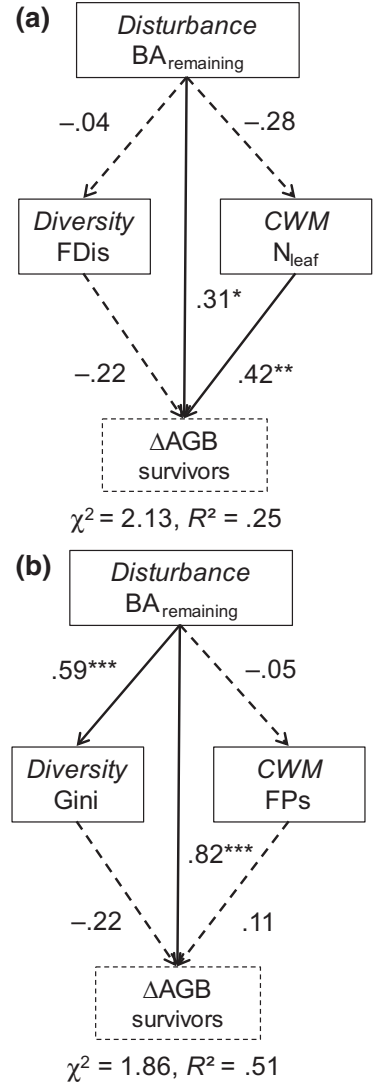

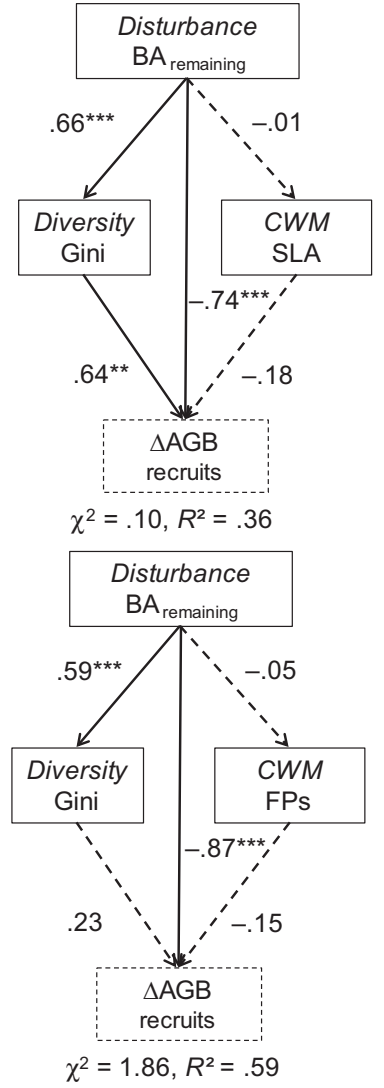

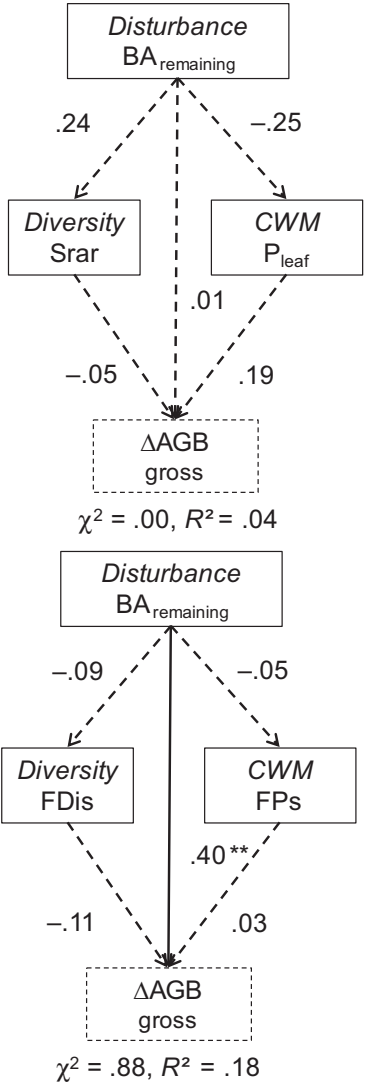

FIGURE 4 Best-fitting structural equation models to explain annual $A G B$ (above-ground biomass) increment $\left(\triangle \mathrm{AGB}, \mathrm{Mg} \mathrm{ha}^{-1}\right.$ year $^{-1}$ ) in dependence of disturbance intensity (expressed as $\mathrm{BA}_{\text {remaining }}$ ), remaining diversity (middle left box) and remaining communityweighted mean (CWM) trait values (middle right box) for each demographic group and in both periods: (a) postlogging and (b) post-thinning. See Table 1 for abbreviations. Significant path coefficients are indicated as continuous arrows and standardised coefficients $(\hat{\beta})$ with associated significance are reported $\left({ }^{*} p<.05,{ }^{* *} p<.01,{ }^{* * *} p<.001\right)$. Values of the chi-square $\left(\chi^{2}\right)$ for the model and the proportion of explained variance $\left(R^{2}\right)$ for $\triangle \mathrm{AGB}$ are provided probably also below-ground. Moreover, recruit trees in post-logging communities are mostly composed of pioneer species that positively respond to canopy opening (de Avila et al., 2015; Yosi et al., 2011). Such contrasting responses of surviving and recruit trees have also been observed in other managed and unmanaged tropical forests (Piponiot et al., 2016; Rutishauser et al., 2010; van der Sande et al., 2017) and underline the importance of evaluating demographic groups separately to better understand AGB dynamics.

\subsection{Niche-complementarity hypothesis: Diversity increased AGB increment only for total community after thinning}

The weak support for the niche-complementarity hypothesis may be associated with the fact that our plots are located in developed and species-rich stands forests where functional redundancy is probably high (Chazdon \& Arroyo, 2013) and niches may be saturated (Loreau \& Mazancourt, 2013). Indeed, positive diversity-growth relationships have been reported to weaken or become negative with forest successional development and increasing diversity in modelling and empirical studies (Holzwarth, Rüger, \& Wirth, 2015; Lasky et al., 2014). We only found significant effects of taxonomic and structural diversity on the $\triangle A G B_{\text {gross }}$ after thinning (Figure 3e). The lack of functional diversity effects on $\triangle A G B$ can be related to the limited set of traits considered here (Wright et al., 2010). Nonetheless, similar to our results, the lack of effect of functional diversity on AGB growth has also been observed during successional development of a wet tropical forest in Mexico (Lohbeck, Poorter, Martínez-Ramos, $\&$ Bongers, 2015), across three mature Neotropical forests (Finegan et al., 2015) and in a managed forest in Bolivia (van der Sande et al., 2017).

\section{3 | Biomass-ratio hypothesis: High leaf nitrogen concentration increased post-logging AGB increment of survivors, but decreased that of recruits}

Annual $A G B$ increment of survivors $\left(\triangle A G B_{\text {survivors }}\right.$ ) increased with the community-weighted mean leaf nitrogen concentration (CWM $\mathrm{N}_{\text {leaf }}$; Figure $2 \mathrm{~d}$ ). This result is likely related to the fact that high $\mathrm{N}_{\text {leaf }}$ leads to increased photosynthetic capacity (Wright et al., 2004) and therefore to a higher potential for growth and carbon accumulation (Poorter, Bongers, \& Bongers, 2006). The negative relationship between $\triangle \mathrm{AGB}_{\text {recruits }}$ and $C W M \mathrm{~N}_{\text {leaf }}$ (Figure 2e) may be associated with a high abundance of species that grow fast in the survivor's community and may hinder the growth of recruit trees, which are more susceptible to competition (Weiner, 1990). Ultimately, the weak support for the biomass-ratio hypothesis may be related to the fact that instead of traits of many dominant species, some particular species with specific traits may drive ecosystem processes (i.e. the selection effect; Loreau, 2000). Here, we found that only 10 tree species contributed to around $40 \%$ of the $\triangle A G B$ at the community level following both logging and thinning (Table S7). Among these species, Tachigali chrysophylla had the highest increment values. This species has high growth rates and commonly responds 
positively in terms of recruitment and growth following silvicultural interventions in forests of the region. Additionally, the post-logging and post-thinning increase in trees of the genera Inga and Cecropia, which consist mainly or exclusively of pioneer species, contributed substantially to AGB increment.

\subsection{Disturbance intensity overrides tree- community attribute effects on AGB recovery}

Disturbance intensity (measured as basal area remaining) was consistently more important for explaining $\triangle A G B$ than remaining diversity and CWM of acquisitive traits in the structural equation models (Figure 4). Disturbance is a major driver of vegetation dynamics (White \& Pickett, 1985) and, therefore, it is not surprising that it played a major role. However, we expected that diversity and the CWM of acquisitive traits of dominant species in the remaining tree community would enhance biomass recovery due to improved resource use and acquisition, but this was not the case. Similar results have been reported for other tropical forests, where standing biomass of the remaining vegetation was the main driver of biomass dynamics instead of diversity or CWM trait values (Lohbeck et al., 2015; van der Sande et al., 2017).

\section{5 | Management implications}

The positive effect of basal area remaining on $\triangle A G B$ of survivors and the fact that growth of surviving trees contributed most to community AGB recovery, as also found in a regional study in the Amazon Basin (Piponiot et al., 2016), points to the importance of controlling management intensity. Furthermore, given that harvesting intensity determines the recovery time of carbon stocks (Rutishauser et al., 2015) and the relative recovery in biodiversity (Burivalova, Sekercioglu, \& Koh, 2014) and species composition (de Avila et al., 2015), it is important to identify the management intensity to which tropical forests are able to absorb disturbances and subsequently recover different properties and functions across felling cycles (Chazdon \& Arroyo, 2013). Our findings indicated that AGB recovery may be impaired with decreasing basal area remaining following logging. Moreover, reduction in basal area in our experiment were on average substantially higher than harvesting intensities permitted by the current legislation for the Brazilian Amazon $\left(30 \mathrm{~m}^{3} / \mathrm{ha}\right.$; Ministry of Environment, 2006). Thus, we presume that current logging practices will likely not impair biomass recovery in these forests.

Accordingly, our results also demonstrate that low to moderate intervention intensities can maintain and even enhance the potential for carbon sequestration of these forests. AGB increment was higher in managed (on average $7.0 \mathrm{Mg} \mathrm{ha}^{-1}$ year $^{-1}$ across both recovery periods) than in unmanaged (5.8 $\mathrm{Mg} \mathrm{ha}^{-1}$ year $^{-1}$ ) plots. However, the net-benefit for climate change mitigation depends ultimately on the fate of the wood products derived from harvested timber (Nabuurs et al., 2007). Our study further indicates that a large part of the AGB recovery is driven by few species and, despite the minor influence of remaining tree-community attributes, their effects should be further investigated over large spatial and temporal scales as they may become important in face of climate change and increasing frequency and severity of human interventions.

\section{ACKNOWLEDEGEMENTS}

We thank Embrapa and all colleagues who have been engaged in this experiment and field inventories. The long-term experiment received financial support from the National Council for Scientific and Technological Development (CNPq, project code 483831/2011-5) and Embrapa (SEG.03.12.00.030.00). A.L.deA. was financially supported by the German Academic Exchange Service (DAAD) (PhD scholarship) and by the Müller-Fahnenberg Foundation for her fieldwork. MPC, LP and MvdS were partially funded by the European Union Seventh Framework Programme (FP7/2007-2013) under grant agreement no. 283093 - The Role Of Biodiversity In climate change mitigatioN (ROBIN), and MvdS was additionally funded by the strategic research program KBIV (KB-14) "Sustainable spatial development of ecosystems, landscapes, seas and regions", funded by the Dutch Ministry of Economic Affairs and carried out by Wageningen University \& Research centre (project code KB-14-003-030). The trait collection received financial support from the ROBIN-project, Stichting Het Kronendak, Alberta Mennega Stichting, and the Treub Maatschappij.

\section{AUTHORS' CONTRIBUTIONS}

A.L.deA., J.B., M.T.vanderS., C.F.D, M.P.-C. and L.P. designed the research; A.R.R., L.M., J.N.M.S., J.O.P.deC., A.L.deA. and M.T.vanderS. collected the data; A.L. de A. performed the analyses and wrote the first draft of the manuscript. All authors contributed substantially to revisions and gave final approval for publication.

\section{DATA ACCESSIBILITY}

Data available from the Dryad Digital Repository https://doi. org/10.5061/dryad.cp8bh43 (de Avila et al., 2018).

\section{ORCID}

Angela L. de Avila (iD http://orcid.org/0000-0001-8291-7936

Masha T. van der Sande (iD http://orcid.org/0000-0002-6845-2308

\section{REFERENCES}

Assmann, E. (1961). Waldertragskunde. Organische Produktion, Struktur, Zuwachs und Ertrag von Waldbeständen. Muenchen: BLV Verlagsgesellschaft.

Burivalova, Z., Sekercioglu, Ç. H., \& Koh, L. P. (2014). Thresholds of logging intensity to maintain tropical forest biodiversity. Current Biology, 24, 1893-1898. https://doi.org/10.1016/j.cub.2014.06.065

Chave, J., Coomes, D., Jansen, S., Lewis, S. L., Swenson, N. G., \& Zanne, A. E. (2009). Towards a worldwide wood 
economics spectrum. Ecology Letters, 12, 351-366. https://doi. org/10.1111/j.1461-0248.2009.01285.x

Chave, J., Réjou-Méchain, M., Búrquez, A., Chidumayo, E., Colgan, M. S., Delitti, W. B. C., ... Vieilledent, G. (2014). Improved allometric models to estimate the aboveground biomass of tropical trees. Global Change Biology, 20, 3177-3190. https://doi.org/10.1111/gcb.12629

Chazdon, R. L. (2003). Tropical forest recovery: Legacies of human impact and natural disturbances. Perspectives in Plant Ecology, Evolution and Systematics, 6, 51-71. https://doi.org/doi:10.1078/1433-831900042

Chazdon, R. L., \& Arroyo, J. P. (2013). Tropical forest as complex adaptive systems. In C. Messier, K. J. Puettmann, \& D. K. Coates (Eds.), Managing forests as complex adaptive systems: Building resilience to the challenge of global change (pp. 35-59). New York, NY: Routledge.

Chazdon, R. L., Letcher, S. G., van Breugel, M., Martínez-Ramos, M., Bongers, F., \& Finegan, B. (2007). Rates of change in tree communities of secondary Neotropical forests following major disturbances. Philosophical Transactions of the Royal Society of London. Series B, Biological Sciences, 362, 273-289. https://doi.org/10.1098/ rstb. 2006.1990

de Avila, A. L., Ruschel, A. R., de Carvalho, J. O. P., Mazzei, L., Silva, J. N. M., Lopes, J. D. C., ... Bauhus, J. (2015). Medium-term dynamics of tree species composition in response to silvicultural intervention intensities in a tropical rain forest. Biological Conservation, 191, 577586. https://doi.org/10.1016/j.biocon.2015.08.004

de Avila, A. L., van der Sande, M. T., Dormann, C. F., Peña-Claros, M., Poorter, L., Mazzei, L., ... Bauhus, J. (2018). Data from: Disturbance intensity is a stronger driver of biomass recovery than remaining tree-community attributes in a managed Amazonian forest. Dryad Digital Repository, https://doi.org/10.5061/dryad.cp8bh43

de Graaf, N. R., Poels, R. L. H., \& van Rompaey, R. S. A. R. (1999). Effect of silvicultural treatment on growth and mortality of rainforest in Surinam over long periods. Forest Ecology and Management, 124, 123-135. https://doi.org/10.1016/S0378-1127(99)00057-2

De Oliveira Junior, R. C., Keller, M. M., da F. Ramos, J. F., Beldini, T. P., Crill, P. M., de Camargo, P. B., \& van Haren, J. (2015). Chemical analysis of rainfall and throughfall in the Tapajós National Forest, Belterra, Pará, Brazil. Ambiente \& Agua - An Interdisciplinary. Journal of Applied Science, 10, 263-285. https://doi.org/10.4136/1980993x

Feldpausch, T. R., McDonald, A. J., Passos, C. A. M., Lehmann, J., \& Riha, S. J. (2006). Biomass, harvestable area, and forest structure estimated from commercial timber inventories and remotely sensed imagery in southern Amazonia. Forest Ecology and Management, 233, 121-132. https://doi.org/10.1016/j.foreco.2006.06.016

Finegan, B., Peña-Claros, M., Oliveira, A., Ascarrunz, N., Bret-Harte, M. S., Carreño-Rocabado, G., ... Poorter, L. (2015). Does functional trait diversity predict aboveground biomass and productivity of tropical forests? Testing the biomass ratio-, niche complementarity, and green soup hypotheses. Journal of Ecology, 103, 191-201. https://doi. org/10.1111/1365-2745.12346

Grace, J. B. (2006). Structural equation modelling and natural systems. New York, NY: Cambridge University Press. https://doi.org/10.1017/ CBO9780511617799

Grime, J. P. (1998). Benefits of plant diversity to ecosystems: immediate, filter and founder effects. Journal of Ecology, 86, 902-910. https:// doi.org/10.1046/j.1365-2745.1998.00306.x

Handcock, M. S. (2015). reldist: Relative distribution methods. R Foundation for Statistical Computing. http://www.stat.ucla.edu/ handcock/ RelDist

Holzwarth, F., Rüger, N., \& Wirth, C. (2015). Taking a closer look: Disentangling effects of functional diversity on ecosystem functions with a trait-based model across hierarchy and time. Royal Society Open Science, 2, 140541. https://doi.org/10.1098/rsos.140541
Kitajima, K., Llorens, A. M., Stefanescu, C., Timchenko, M. V., Lucas, P. W., \& Wright, S. J. (2012). How cellulose-based leaf toughness and lamina density contribute to long leaf lifespans of shadetolerant species. New Phytologist, 195, 640-652. https://doi. org/10.1111/j.1469-8137.2012.04203.x

Laliberté, E., Legendre, P., \& Shipley, B. (2015). FD: Measuring functional diversity (FD) from multiple traits, and other tools for functional ecology. Retrieved from https://cran.r-project.org/web/packages/ FD/FD.pdf

Lasky, J. R., Uriarte, M., Boukili, V. K., Erickson, D. L., John Kress, W., \& Chazdon, R. L. (2014). The relationship between tree biodiversity and biomass dynamics changes with tropical forest succession. Ecology Letters, 17, 1158-1167. https://doi.org/10.1111/ele.12322

Lohbeck, M., Poorter, L., Martínez-Ramos, M., \& Bongers, F. (2015). Biomass is the main driver of changes in ecosystem process rates during tropical forest succession. Ecology, 96, 1242-1252. https:// doi.org/10.1890/14-0472.1

Loreau, M. (2000). Biodiversity and ecosystem functioning: Recent theoretical advances. Oikos, 91, 3-17. https://doi. org/10.1034/j.1600-0706.2000.910101.x

Loreau, M., \& de Mazancourt, C. (2013). Biodiversity and ecosystem stability: A synthesis of underlying mechanisms. Ecology Letters, 16(Suppl. 1), 106-115. https://doi.org/10.1111/ele.12073 https:// doi.org/10.1111/ele.12073

Mazzei, L., Sist, P., Ruschel, A., Putz, F. E., Marco, P., Pena, W., \& Ferreira, J. E. R. (2010). Above-ground biomass dynamics after reduced-impact logging in the Eastern Amazon. Forest Ecology and Management, 259, 367-373. https://doi.org/10.1016/ j.foreco.2009.10.031

Mercado, L. M., Patino, S., Domingues, T. F., Fyllas, N. M., Weedon, G. P., Sitch, S., ... Lloyd, J. (2011). Variations in Amazon forest productivity correlated with foliar nutrients and modelled rates of photosynthetic carbon supply. Philosophical Transactions of the Royal Society B: Biological Sciences, 366, 3316-3329. https://doi.org/10.1098/ rstb. 2011.0045

Miller, S. D., Goulden, M. L., Hutyra, L. R., Keller, M., Saleska, S. R., Wofsy, S. C., ... de Camargo, P. B. (2011). Reduced impact logging minimally alters tropical rainforest carbon and energy exchange. Proceedings of the National Academy of Sciences of the United States of America, 108, 19431-19435. https://doi.org/10.1073/pnas.1105068108

Ministry of Environment (MMA). (2006). Instrução Normativa $N^{\circ} 5$ de 11 de dezembro de 2006. Brasília: Ministry of Environment.

Nabuurs, G. J., Masera, O., Andrasko, K., Benitez-Ponce, P., Boer, R., Dutschke, M, ... Zhang, X. (2007). Forestry. In B. Metz, O. R. Davidson, P. R. Bosch, R. Dave \& L. A. Meyer (Eds.), Climate Change 2007: Mitigation. Contribution of Working Group III to the Fourth Assessment Report of the Intergovernmental Panel on Climate Change (pp. 541584). Cambridge, UK and New York, NY: Cambridge University Press.

Pakeman, R. J. (2014). Functional trait metrics are sensitive to the completeness of the species' trait data? Methods in Ecology and Evolution, 5, 9-15. https://doi.org/10.1111/2041-210X.12136

Peel, M. C., Finlayson, B. L., \& McMahon, T. A. (2007). Updated world map of the Köppen-Geiger climate classification. Hydrology and Earth System Sciences, 11, 1633-1644. https://doi.org/doi:10.5194/ hess-11-1633-2007

Pérez-Harguindeguy, N., Díaz, S., Garnier, E., Lavorel, S., Poorter, H., Jaureguiberry, P., ... Cornelissen, J. H. (2013). New handbook for standardized measurement of plant functional traits worldwide. Australian Journal of Botany, 61, 167-234. https://doi.org/doi: 10.1071/BT12225

Pinheiro, J., Bates, D., DebRoy, S., \& Sarkar, D. (2015). nlme: Linear and nonlinear mixed effects models. R-Core. Retrieved from http:// cran.r-project.org/web/packages/nlme/nlme.pdf

Piponiot, C., Sist, P., Mazzei, L., Pena-Claros, M., Putz, F. E., Rutishauser, E, ... Hérault, B. (2016). Carbon recovery dynamics following disturbance 
by selective logging in Amazonian forests. eLife, 5, e21394, 1-19. https://doi.org/10.7554/elife.21394

Poorter, L., Bongers, L., \& Bongers, F. (2006). Architecture of 54 moistforest tree species: Traits, trade-offs, and functional groups. Ecology, 87, 1289-1301. Retrieved from http://www.ncbi.nlm.nih.gov/ pubmed/16761607 https://doi.org/10.1890/0012-9658(2006)87[1 289:AOMTST]2.0.CO;2

Poorter, L., Wright, S. J., Paz, H., Ackerly, D. D., Condit, R., IbarraManríquez, G., ... Wright, I. J. (2008). Are functional traits good predictors of demographic rates? Evidence from five neotropical forests Ecology, 89, 1908-1920. https://doi.org/10.1890/07-0207.1

R Development Core Team. (2014). R: A language and environment for statistical computing. Vienna, Austria: R Foundation for Statistical Computing. Retrieved from http://www.r-project.org/

Rosseel, Y., Oberski, D., Byrnes, J., Vanbrabant, L., Savalei, V., Merkle, E., ... Barendse, M. (2015). lavaan: Latent variable analysis. Retrieved from https://cran.r-project.org/web/packages/lavaan/lavaan.pdf

Rutishauser, E., Hérault, B., Baraloto, C., Blanc, L., Descroix, L., Sotta, E. D., ... Sist, P. (2015). Rapid tree carbon stock recovery in managed Amazonian forests. Current Biology, 25, R787-R788. https://doi.org/10.1016/j. cub.2015.07.034

Rutishauser, E., Wagner, F., Herault, B., Nicolini, E.-A., \& Blanc, L. (2010). Contrasting above-ground biomass balance in a Neotropical rain forest. Journal of Vegetation Science, 21, 672-682. Retrieved from http:// www.jstor.org/stable/40925523

Shipley, B. (2006). Net assimilation rate, specific leaf area and leaf mass ratio: Which is most closely correlated with relative growth rate? A meta-analysis Functional Ecology, 20, 565-574. https://doi. org/10.1111/j.1365-2435.2006.01135.x

Talbot, J., Lewis, S. L., Lopez-Gonzalez, G., Brienen, R. J. W., Monteagudo, A., Baker, T. R., ... Phillips, O. L. (2014). Methods to estimate aboveground wood productivity from long-term forest inventory plots. Forest Ecology and Management, 320, 30-38. https://doi. org/10.1016/j.foreco.2014.02.021

van der Sande, M. T., Peña-Claros, M., Ascarrunz, N., Arets, E. J. M. M., Licona, J. C., Toledo, M., \& Poorter, L. (2017). Abiotic and biotic drivers of biomass change in a Neotropical forest. Journal of Ecology, 105, 1223-1234. https://doi.org/10.1111/1365-2745.12756

Vidal, E., West, T. A. P., \& Putz, F. E. (2016). Recovery of biomass and merchantable timber volumes twenty years after conventional and reduced-impact logging in Amazonian Brazil. Forest Ecology and Management, 376, 1-8. https://doi.org/10.1016/j.foreco.2016.06.003

Violle, C., Navas, M. L., Vile, D., Kazakou, E., Fortunel, C., Hummel, I., \& Garnier, E. (2007). Let the concept of trait be functional!. Oikos, 116, 882-892. https://doi.org/10.1111/j.2007.0030-1299.15559.x
Weiner, J. (1990). Asymmetric competition in plant populations. Trends in Ecology \& Evolution, 5, 360-364. https://doi. org/10.1016/0169-5347(90)90095-U

Weiner, J., \& Solbrig, O. T. (1984). The meaning and measuring of size hierarchies in plant populations. Oecologia, 61, 334-336. https://doi. org/10.1007/BF00379630

West, T. A. P., Vidal, E., \& Putz, F. E. (2014). Forest biomass recovery after conventional and reduced-impact logging in Amazonian Brazil. Forest Ecology and Management, 314, 59-63. https://doi.org/10.1016/ j.foreco.2013.11.022

White, P. S., \& Pickett, S. T. A. (1985). Natural disturbance and patch dynamics: An introduction. In S. T. A. Pickett, \& P. S. White (Eds.), The ecology of natural disturbance and patch dynamics (pp. 3-13). San Diego, CA: Academic Press.

Wright, S. J., Kitajima, K., Kraft, N. J. B., Reich, P. B., Wright, I. J., Bunker, D. E., ... Zanne, A. E. (2010). Functional traits and the growthmortality trade-off in tropical trees. Ecology, 91, 3664-3674. https:// doi.org/10.1002/ece3.1186

Wright, I. J., Reich, P. B., Westoby, M., Ackerly, D. D., Baruch, Z., Bongers, F., ... Villar, R. (2004). The worldwide leaf economics spectrum. Nature, 428, 821-827. https://doi.org/10.1038/nature02403

Yosi, C. K., Keenan, R. J., \& Fox, J. C. (2011). Forest dynamics after selective timber harvesting in Papua New Guinea. Forest Ecology and Management, 262, 895-905. https://doi.org/10.1016/j. foreco.2011.06.007

Zanne, A. E., Lopez-Gonzalez, G., Coomes, D. A., llic, J., Jansen, S., Lewis, S. L., ... Chave, J. (2009). Data from: Towards a worldwide wood economics spectrum. Dryad Digital Repository, https://doi.org/10.5061/ dryad. 234

\section{SUPPORTING INFORMATION}

Additional Supporting Information may be found online in the supporting information tab for this article.

How to cite this article: de Avila AL, van der Sande MT, Dormann CF, et al. Disturbance intensity is a stronger driver of biomass recovery than remaining tree-community attributes in a managed Amazonian forest. J Appl Ecol. 2018;55:1647-1657. https://doi.org/10.1111/1365-2664.13134 